\title{
COMENTARIOS DE LIBROS
}


Libro:

Traducción del original:

Autor:

Editorial
El Cerebro Ejecutivo: Lóbulos Frontales y Mente Civilizada.

"The Executive Brain: Frontal Lobes and the Civilized Mind", 2001.

Elkhonon Goldberg, PhD

Oxford University Press, 2002
De origen ruso, Goldberg fue estudiante y amigo de Alexander Luria (autor de Funciones Corticales Superiores), con quien mantuvo una importante y decisiva relación en su vida. Emigró a Estados Unidos y actualmente vive en Nueva York. Divide su tiempo entre la Practica Neurológica y la investigación en Neurociencia Cognitiva. Tiene el cargo de Profesor clínico de Neurología en la Escuela de Medicina de la Universidad de Nueva York, y es director del Instituto de Neuropsicología y Desempeño Cognitivo.

Este libro tiene un doble mérito para el público de habla hispana. Su traducción al español, por una parte, y por otra, que a pesar de ser un libro científicamente riguroso, también lo es de divulgación. Explora la región del cerebro considerada por él mismo "más humana", los lóbulos frontales, en un lenguaje accequible y ameno. Goldberg describe cómo los lóbulos frontales nos permiten comprometernos en procesos mentales complejos, como controlan nuestro juicio y sentido común, y nuestra conducta ética y social.

Durante mucho tiempo, desde los inicios científicos de la Neuropsicología a fines del s.xx, se tuvo una visión poco clara de las funciones de los lóbulos frontales. Esto resultaba de la escasa sintomatología que presentaban cuando dañados (por ejemplo en los resultados de pruebas de $\mathrm{CI}$ )., lo que era considerado desproporcionado si se comparaba con el enorme desarrollo que tuvieron a través de la escala filogenética. Esta visión cambió en las últimas décadas del s. XX, a partir de los avances de las técnicas de imágenes e investigación en pacientes con daño cerebral, el mayor refinamiento de las evaluaciones neuropsicológicas y los aportes de la neuroanatomía y neurofisiología sobre las conexiones y redes neuronales del cerebro, lo que ha permitido comprender mejor las sutilezas del comportamiento de los lóbulos frontales. Justamente a esto contribuye este libro.

Goldberg confiesa, a través de su relato, que su interés se inicia en Rusia, al observar lo que sucede con un amigo cuando cae al riel del Metro de Moscú, y es atropellado por el tren. Luego, también, por su intercambio intelectual con Luria, se dedica a estudiar la función de esta área cerebral, más olvidada que otras áreas del cerebro. Nos muestra cuan vulnerables son los lóbulos frontales y cuan devastadores pueden ser los efectos del daño cerebral en esa región, que puede llevar a conductas caóticas, desorganizadas y muchas veces asociales e incluso criminales.

El relato está repleto de casuística fascinante y anécdotas y el libro de Goldberg nos ofrece un panorama actualizado de los avances en Neurociencia Cognitiva. Su dedicación al estudio de los lóbulos frontales radica en el hecho de que considera que es la parte del cerebro que nos hace quienes somos definiendo nuestra identidad, encapsulando (en sus palabras) nuestras motivaciones y ambiciones, nuestra esencia, nuestra personalidad. Si otras partes del cerebro se dañan podemos perder la memoria, la percepción, la comprensión de 
lenguaje, o el movimiento. Pero mantenemos la esencia de nuestra individualidad y el núcleo de nuestra personalidad, en general, permanece intacto. Para él los lóbulos frontales serían la parte más singularmente humana de todas las estructuras cerebrales, y piensa que tienen un rol crítico en el éxito o fracaso de cualquiera empresa humana. Los lóbulos frontales llevarían a cabo las funciones más complejas de todo el cerebro, las llamadas funciones ejecutivas. Están relacionados con la intencionalidad, el propósito y la toma de decisiones más complejas. Señala, finalmente, que la evolución humana completa ha sido denominada "la era de los lóbulos frontales" y su profesor, Alexander Luria, a quien dedica el libro, señalaba a su vez que el lóbulo frontal era "el órgano de la civilización."

María de los Angeles Saavedra, PhD Profesor de Neuropsicología Departamento de Psicología Facultad de Ciencias Sociales Universidad de Chile
Libro:

Autoras:

Editorial:
Desarrollo Humano.

Diane E. Papalia, Sally Wendkos Olds y Ruth Duskin Feldman.

Mc Graw-Hill Interamericana, S.A. Bogotá. 2001.
Nos encontramos con la octava edición en español de uno de los libros, sobre Psicología del Desarrollo, más conocidos y utilizados en el medio latino.

En esta obra, los períodos del ciclo vital son entendidos como una construcción social y se adopta la secuencia de edades que gozan de aceptación general en las sociedades industriales de Occidente, con algunas pequeñas diferencias respecto a otros esquemas que ya conocemos: la segunda etapa de la lactancia y primeros pasos se considera hasta los tres años de edad, la niñez temprana desde los tres a los seis años, la adolescencia se entiende que termina hacia los 20 años, la adultez temprana se extiende hasta los 40 años, de los 40 a 65 años se habla de adultez intermedia y se denomina adultez tardía al período final, sobre 65 años.

En la primera parte, que consta de dos capítulos, se trata la historia del estudio sobre el desarrollo, los principios fundamentales, las influencias que operan en el desarrollo de las personas, las perspectivas teóricas y los métodos de investigación. El capítulo 3 está dedicado a los mecanismos hereditarios y al desarrollo prenatal, al modo clásico en Psicología del Desarrollo. En el capítulo 4 se trata el nacimiento y el recién nacido. Los capítulos 5 y 6 se refieren al desarrollo cognitivo-lingüístico y psicosocial respectivamente, durante los tres primeros años de edad. Destacamos el espacio concedido al papel de ambos progenitores, al desarrollo de la confianza básica y al apego. En el capítulo 7 se aborda el desarrollo físico y cognitivo durante la niñez temprana y en el 8 se analiza el desarrollo afectivo y social de la etapa. Realzamos el tratamiento integral de temas tan actuales como la adquisición de la identidad de género, la disciplina y el maltrato. En el capítulo 9, dedicado al desarrollo físico y cognitivo en la niñez intermedia, se 
tocan aspectos prácticos relativos a la salud, a la evaluación intelectual y a la adaptación escolar. El capítulo 10, sobre el desarrollo psicosocial, incorpora el tema de la influencia familiar en las realidades actuales y los problemas más frecuentes del desarrollo emocional en los niños. Los capítulos 11 y 12 están destinados al estudio del complejo período de la adolescencia, con un enfoque que advierte sobre la necesidad de evitar todo etnocentrismo al respecto. En los dos capítulos -13 y 14- dedicados a la adultez temprana, los mejores aportes son sobre la inteligencia postformal propia de esta etapa del desarrollo y los estudios de Sternberg sobre inteligencia creadora y práctica, las que aumentan hasta la edad madura y no son medidas por las pruebas psicométricas. En el capítulo 15, se concede gran espacio a los asuntos relativos a la salud y se continúa ahondando en la naturaleza integradora del pensamiento postformal, con referencias empíricas. En el capítulo 16, ocupan lugar preferente los modelos de Jung, de Erikson y de sus seguidores más modernos Vaillant y Levison. Los capítulos 17 y 18, sobre la adultez tardía, contienen las teorías del envejecimiento, los problemas mentales de la edad, la medición de la inteligencia en las personas mayores, los estudios longitudinales de
Seatle, la adquisición de sabiduría y el ajuste personal-social. Como en todo texto moderno sobre desarrollo, se incluyen algunas páginas - el epílogo- sobre la muerte. En éste destacan las siempre presentes etapas en el afrontamiento de este trance, según Kubler- Ross, las ideas sobre la muerte y el duelo en las distintas etapas de la vida, el suicidio y la eutanasia.

Cada capítulo incluye una guía de estudio, preguntas de evaluación, resumen, términos clave y se acompaña con abundante material fotográfico. Además, se proporciona un glosario de términos básicos. En síntesis, contamos con un texto guía extraordinariamente didáctico, que sirve para introducirse en los temas más importantes de la Psicología del Desarrollo. Esta característica lo convierte en un valioso apoyo docente en la formación del pregrado y en un infaltable en la biblioteca personal, no sólo del psicólogo, sino de toda persona que se interese en el conocimiento y comprensión de sí misma y de sus semejantes.

Liliana Vilches Seguel Profesora de Psicología del Desarrollo Departamento de Psicología Facultad de Ciencias Sociales Universidad de chile
Libro :

Autora :

Editorial:
PSICOLOGIA DEL DESARROLLO, perspectivas teórico-metodológicas e inicio de la vida.

Liliana Vilches Seguel

LOM Ediciones Ltda., Santiago de Chile 2002
El libro "Psicología del Desarrollo", presentado por la psicóloga Liliana Vilches ha venido a agregarse a una serie de textos y artículos escritos con anterioridad por ella y que reflejan su interés y erudición en esta disciplina.
A nivel de contenidos se aprecia claramente la existencia de dos áreas: en la primera, que incluye los capítulos uno al cinco, se describen aspectos y temas básicos de la Psicología del Desarrollo y en la segunda, reflexiones y comentarios de la au- 
tora acerca de diversos temas que pueden ser analizados desde una perspectiva psicológica.

Es así, como en el capítulo uno, se describe claramente el objeto de estudio y campo de la Psicología del Desarrollo. Se plantea una interesante propuesta que favorece esta denominación en contraposición a la más tradicional de "Psicología Evolutiva", enfatizando la importancia de la consideración de las particularidades del individuo más bien que el comportamiento que le corresponde por encontrarse en determinada etapa de la vida.

El capítulo 2 se ocupa de los principios generales que rigen el proceso del desarrollo humano y que son aplicables a todos los seres humanos independientemente de las diferencias socioculturales existentes entre ellos.

En el tercer capítulo hay una completa descripción de los métodos utilizados por esta disciplina y que comparte con otras de la Psicología; es el caso por ejemplo, de la observación y la experimentación. Hace referencia también a los métodos y enfoques que son considerados como propios y exclusivos mencionando las técnicas empleadas por ellos.

El capítulo 4 analiza conceptos fundamentales, describiendo perfectamente las diferencias entre ellos. Es así como se estudian las ideas de desarrollo, crecimiento, madurez, maduración, constructos básicos para una adecuada comprensión de esta materia.

Se plantea también en este sector, la clásica controversia entre herencia y ambiente; como referente se utilizan diversos métodos que apuntan a destacar en forma prioritaria el papel que desempeñan uno $u$ otro de estos elementos. La autora, desde una perspectiva interaccionista propone la participación conjunta de ambos factores.

En el capítulo cinco se muestra una panorámica de las principales teorías que se han preocupado del funcionamiento del ser humano. Se describen detalladamente los planteamientos de autores reconocidos por sus aportes a esta disciplina como Piaget y Kohlberg. Asimismo se rescata de otros enfoques, las contribuciones que han hecho teóricos del psicoanálisis (Freud, Jung y otros) del humanismo (Maslow) del aprendizaje social (Bandura) y otros. Es destacable la claridad y sistematización de esta descripción lo que permite al lector detectar fácilmente cuales son las ideas distintivas y más fundamentales de cada uno de ellos.

En la segunda parte del libro, la autora reflexiona acerca de diversos temas y problemas que no constituyen materia de estudios de la Psicología del Desarrollo, pero que pueden ser enfocados desde esta perspectiva. Es así como se pronuncia acerca de la separación familiar, el uso de anticonceptivos de emergencia, el aborto, la infertilidad, la esterilización, la clonación, la censura y otros.

En este sentido, no podría hablarse de neutralidad ya que ella presenta un enfoque particular que, más allá de que lo compartimos o no, constituye un abordaje cuestionador que lleva al lector a revisar sus propias ideas creencias y valores frente a estos temas.

Esta publicación, tal como lo plantea la autora responde a las inquietudes formuladas por sus propios alumnos. Desde este punto de vista creo que logró plenamente su objetivo ya que constituye un elemento valioso como material de apoyo a la doc encia. Es un texto bien escrito, con una redacción comprensible que facilita el aprendizaje gracias a la utilización de cuestionarios, recapitulaciones y lineamientos y actividades prácticas al final de cada capítulo.

Ps. Mónica Rojas Gorigoytia Prof. Departamento de Psicología Fac. de Ciencias Sociales Universidad de Chile 